\title{
Investigação matemática e seu aporte para a aprendizagem
}

\section{RESUMO}

Elaine Cristina Ferruzzi elaineferruzzi@utfpr.edu.br 0000-0003-3378-5185

Universidade Tecnológica Federal do Paraná

Juliana Aparecida Alves da costa julian.mat@hotmail.com

0000-0002-4600-6788

Universidade Tecnológica Federal do Paraná

\begin{abstract}
Este artigo pretende iniciar uma discussão a respeito da Investigação Matemática em sala de aula, argumentando a favor de sua inserção, entendendo-a como auxiliadora no processo de aprendizagem. Para tanto, procuramos identificar no desenvolvimento e análise de algumas atividades a presença de alguns atos, chamados dialógicos, que, caso estejam nas interações, podem nos subsidiar para este entendimento. A presença de alguns destes atos sinaliza, de acordo com Alrø e Skovsmose (2010), que esta interação pode ser caracterizada como diálogo e "interações caracterizadas como 'diálogos' são interações que possuem qualidades que influenciam positivamente a aprendizagem" (Ferruzzi e Almeida, 2015, p. 378). A análise das interações, com base em nosso referencial teórico, nos possibilitou encontrar indícios de que a Investigação Matemática enquanto prática pedagógica propicia o diálogo, e assim inferimos sobre sua capacidade de influenciar positivamente a aprendizagem.
\end{abstract}

PALAVRAS-CHAVE: Diálogo. Investigação matemática. Aprendizagem. 


\section{INTRODUÇÃO}

O resultado do Programme for International Student Assessment - PISA/2015, apresenta índices deveras preocupantes em relação à Educação Brasileira, em especial, a constatação de que estamos muito abaixo da média mundial na área de matemática: $66^{\circ}$ lugar de um total de 72 países (OCDE, 2016). Infelizmente estes dados têm sido corroborados empiricamente em sala de aula, evidenciando a necessidade de mudanças no processo de ensino da matemática escolar brasileira. Neste sentido, o constante debate sobre este tema tem conduzindo diversos pesquisadores da área da Educação Matemática à busca por um ensino que promova efetivamente a aprendizagem (CUNHA, 2009).

Levando em consideração que "Ensinar bem matemática é um empenho complexo e não há receitas fáceis para isso" (Onuchic; Allevato, 2004, p. 214), alguns educadores têm se mobilizado ao estudo das diversas práticas pedagógicas que podem ser desenvolvidas em sala de aula com vistas a minimizar o problema constatado.

Considerando esta diversidade de práticas evidenciadas na atualidade, entendemos, assim como Rocha (1980), que não existem metodologias que possam ser consideradas modelo-padrão de eficácia para a aprendizagem. Acreditamos que a escolha de uma ou outra, ou até mesmo a junção de duas ou mais, está intimamente relacionada ao estilo do professor, às características de seus alunos e ao tema a ser tratado. Desse modo, levando em consideração esses fatores, a escolha do professor terá maior possibilidade de influenciar positivamente a aprendizagem.

Dentre as diversas metodologias, optamos, neste momento, por estudar a Investigação Matemática como prática pedagógica. Para esta escolha levamos em consideração a perspectiva da Educação Matemática Crítica defendida por Alro e Skovsmose (2006) em que consideram que opções metodológicas que adotam uma abordagem investigativa são propícias para abrirem espaços para novas comunicações, conduzindo a novas qualidades da comunicação à medida que os alunos se tornam condutores do processo, participando ativamente. Desse modo, nosso estudo e posterior análise se deram em termos de diagnosticar se a Investigação Matemática em sala de aula propicia o diálogo, como caracterizado por Alrø e Skovsmose (2010), haja vista que na concepção destes autores as "interações caracterizadas como "diálogos" são interações que possuem qualidades que influenciam positivamente a aprendizagem" (Ferruzzi; Almeida, 2015 , p. 378). Assim, se o diálogo influencia positivamente a aprendizagem, então, a ocorrência deste em atividades de Investigação Matemática nos proporciona subsídios para inferir que a Investigação Matemática influencia positivamente a aprendizagem.

Com o intuito de subsidiar nossa análise, descreveremos na sequência nosso aporte teórico, constituído pela Investigação Matemática como prática pedagógica e pelo diálogo em sala de aula.

\section{APORTE TEÓRICO}

\subsection{Investigação Matemática como prática pedagógica}


As atividades de Investigação Matemática como prática pedagógica têm conquistado espaço no Ensino de Matemática com vistas a permitir ao aluno aprender matemática fazendo matemática. Para Oliveira, Segurado e Ponte (1999), a Investigação Matemática busca aproximar o aluno do trabalho desenvolvido pelos matemáticos profissionais, no que se refere à utilização de artifícios e estrutura de forma aceitável.

Esta prática pedagógica faz referência a investigar para tomar conhecimento daquilo que não se sabe, utilizando, para isto, um conjunto de processos peculiares da atividade matemática. Investigar tem suas particularidades, onde o investigador procura formular questões que posteriormente serão testadas e comprovadas (ou não), quando necessário. Esta ação configura-se uma importante ferramenta, pois, quando trabalhada adequadamente, conduz o aluno a construção do conhecimento (PONTE; BROCARDO; OLIVEIRA, 2013).

Para diversos pesquisadores, como, Fonseca (2000), Oliveira (1998), Brunheiras (2000), Brocardo (2001) e Varandas (2000), as aulas ministradas por meio da Investigação Matemática possibilitam um novo olhar para a matemática, posto que uma aula investigativa suscita mudança de atitude de ambos os lados: para o professor, uma reflexão associada a uma análise sobre sua prática de ensino e, para os alunos, uma visão de matemática mais consistente.

Trabalhar com atividades de Investigação Matemática em sala de aula possibilita aos alunos estudar conceitos matemáticos presentes no contexto das atividades, ampliando ou aprimorando suas múltiplas capacidades, como a criatividade, a interpretação, a reflexão, a argumentação, a sistematização e a autonomia. Assim, diante desses benefícios inerentes, e tendo em vista que o caminho percorrido é de extrema importância, entendemos que os conceitos matemáticos estudados em uma atividade de investigação não precisam ser necessariamente conceitos novos ou inacessíveis ao estudante, tendo em vista que a apresentação de atividades insolúveis tende a frustrar o estudante, e esse não é o objetivo. Como salienta Ponte, Brocardo e Oliveira (2013, p.9), trabalhar com atividades de investigação

[...] não representa obrigatoriamente trabalhar em problemas muito difíceis. Significa, pelo contrário, trabalhar com questões que nos interpelam e que se apresentam no início de modo confuso, mas que procuramos clarificar e estudar de modo organizado.

Um ponto essencial dessa prática pedagógica é que, além da interação natural que deve ocorrer em virtude das equipes formadas, é aconselhado que os alunos compartilhem com os colegas as suas estratégias de resolução. Consideramos, assim como Ponte (2013), que esse momento é extremamente significativo, pois os alunos têm a oportunidade de refletir sobre os processos desenvolvidos e entendê-los profundamente para explicar e convencer os colegas. Nesse sentido Onrubia (1999) corrobora com nosso entendimento, considerando que

[...] a tentativa de formular verbalmente a própria representação para comunicá-la aos demais obriga a reconsiderar e reanalisar aquilo que se pretende transmitir; ajuda a detectar incongruências e incorreções; força a ser mais explícitos e precisos; obriga a buscar formulações alternativas para uma mesma ideia; ajuda, em suma, a rever e enriquecer o próprio ponto de vista (p. 146). 
Por outro lado, para que os alunos se sintam motivados frente a uma Investigação Matemática, é preciso que o professor os estimule a seguir em frente. Para isso, é necessário que o professor se sinta confiante e que tenha como objetivo conduzir o aluno a interagir com o que está aprendendo, e mais, procurar desenvolver nos alunos atitudes como, por exemplo, criar estratégias e tomar decisões, pois este processo contribui para que os alunos tornem-se construtores do seu próprio conhecimento (PONTE; BROCARDO; OLIVEIRA, 2013).

Em vista disso, um ator essencial para que a sala de aula se torne um ambiente investigativo é, sem dúvida, o professor. Cabe a ele iniciar e dirigir a discussão, envolver os alunos, cultivar o interesse pelo assunto, propor questões que esclareçam ou estimulem. Além disso, deverá aceitar as contribuições de todos os alunos, não somente daqueles que têm habitualmente respostas corretas ou ideias apropriadas (OLIVEIRA; SEGURADO; PONTE, 1999).

Na concepção de Cyrino (2002, p. 3), “o professor deve assumir uma atitude investigativa, considerando a produção do conhecimento como uma construção coletiva", deixando de ser o centro do saber, passando a ser um orientador. Com isso, o seu papel muda de "comunicador de conhecimento para o de observador, organizador, consultor, mediador, interventor, controlador e incentivador da aprendizagem" (ONUCHIC, 1999, p. 216). O professor precisa ainda ser capaz de orientar a comunicação entre os alunos, procurando reconhecer o papel da linguagem não oral, buscando promover a linguagem matemática, sem que esta seja imposta (PONTE et al., 1999).

\subsection{Diálogo e aprendizagem em sala de aula}

Quando se trata de aulas com abordagem investigativa, cabe ao professor "desafiar os alunos, avaliar seu progresso, raciocinar matematicamente e apoiar o trabalho deles" (Ponte, Brocardo e Oliveira, 2013, p. 47). Para isso, o professor deve analisar o grau de conhecimento dos seus alunos, para saber o que esperar de retorno, e assim estar preparado para lidar com possíveis dificuldades que possam surgir (PORFÍRIO; OLIVEIRA, 1999).

Para Alrø e Skovsmose (2010, p.12) o diálogo é

[...] uma experiência pessoal, mas ela ocorre em contextos sociais repletos de relações interpessoais. E, por conseguinte, a aprendizagem depende da qualidade do contato nas relações interpessoais que manifesta durante a comunicação entre os participantes.

Esta qualidade do contato é influenciada pelos atores da comunicação, tendo em conta que, por ser uma relação interpessoal, "esta ocorre entre sujeitos distintos com personalidades e pensamentos diferentes, assim, cada um possuirá uma perspectiva própria sobre o objeto da comunicação" (SCHIMIGUEL, et al., 2016, p. 116).

Brouwer, citado em Skovsmose (2001, p 25), vai mais além, quando considera que a própria matemática "é uma construção humana" e, portanto, deve ter em vista as relações entre aluno e professor, e no nosso entender, entre alunos e alunos igualmente. 
Para Alrø e Skovsmose (2010), uma conversação que tem como princípio a aprendizagem pode ser entendida como um diálogo, em que os participantes são influenciados e sofrem mudanças ao longo do processo (FERRUZZI; ALMEIDA, 2015). Alguns aspectos dessa conversação tendem a influenciar essa mudança e, consequentemente, o sucesso da aprendizagem dos alunos. Dentre esses aspectos destacam-se: realizar uma investigação, correr riscos e promover a igualdade (ALR $\varnothing$; SKOVSMOSE, 2010).

Realizar uma investigação consiste em sair da zona de conforto e se deixar levar pela curiosidade e pela busca do até então desconhecido. Correr riscos está em acreditar que algo imprevisto pode ocorrer e que não há respostas prontas de antemão. Promover a igualdade significa saber lidar com a diversidade e as diferenças e, com isso, a forma de contato é essencial para que uma desigualdade vista como natural seja favorecida.

Pensando na ocorrência do diálogo, Alrø e Skovsmose (2010) apresentam algumas características denominadas atos dialógicos que são considerados importantes no processo, tais como: estabelecer contato, perceber, reconhecer, posicionar-se, pensar alto, reformular, desafiar e avaliar. O Quadro 01 apresenta uma síntese de cada ato dialógico conforme a caracterização dos autores mencionados.

Quadro 1- Síntese dos atos dialógicos caracterizados por Alro e Skovsmose (2010)

\begin{tabular}{|c|c|}
\hline Estabelecer Contato & Sintonizar-se com o outro e com suas perspectivas. \\
\hline Perceber & $\begin{array}{l}\text { Constatar algo de que não se tenha conhecimento, ou examinar como o } \\
\text { "outro" entende certa situação, e isto engloba indagar suas crenças e } \\
\text { observá-las conjuntamente, aceitando-as ou rejeitando-as (FERRUZZI; } \\
\text { ALMEIDA 2015). }\end{array}$ \\
\hline Reconhecer & $\begin{array}{l}\text { Examinar perspectivas e ideias, fazendo com que todos os envolvidos na } \\
\text { investigação tenham conhecimento. }\end{array}$ \\
\hline Posicionar-se & $\begin{array}{l}\text { Expor pensamentos, realizar declarações ou apresentar argumentos, como } \\
\text { também, aceitar críticas com o intuito de investigar conjuntamente um } \\
\text { assunto ou perspectiva. (FERRUZZI; ALMEIDA, 2015). }\end{array}$ \\
\hline Pensar Alto & $\begin{array}{l}\text { "[...] significa expressar pensamentos, ideias e sentimentos durante o } \\
\text { processo de investigação. Expressar o que se passa dentro de si expõe as } \\
\text { perspectivas à investigação coletiva" (ALRO; SKOVSMOSE, 2006, p. 113). }\end{array}$ \\
\hline Reformular & $\begin{array}{l}\text { Repetir ideias ou sugestões suas ou de outros participantes, confirmando } \\
\text { o que se ouviu, como um convite para uma reflexão maior, ou } \\
\text { confirmação de que possuem o mesmo entendimento. }\end{array}$ \\
\hline Desafiar & $\begin{array}{l}\text { Conduzir para outra direção ou questionar conhecimentos ou perspectivas } \\
\text { já estabelecidas. }\end{array}$ \\
\hline Avaliar & Pode assumir diversas formas que pressupõem apoio, crítica e feedback. \\
\hline
\end{tabular}

(Fonte: Alrø e Skovsmose, 2010)

Os atos dialógicos apresentados no Quadro 1são parte de um mesmo processo integrado à investigação, não sendo necessário que ocorram todos ao mesmo tempo, e nem que sigam a mesma ordem do texto (ALR $\varnothing$; SKOVSMOSE, 2010).

Diante do exposto, nossa pesquisa caminhou no sentido de identificar, em atividades de Investigação Matemática, a presença de atos dialógicos que configuram o diálogo, como o caracterizado pelos autores supracitados, levando em consideração que a ocorrência do mesmo nos concede argumentos para inferir que a Investigação Matemática como prática pedagógica influencia positivamente a aprendizagem. 
Entendemos que as ideias de João Pedro da Ponte concernente às atividades investigativas e as de Helen Alro e Ole Skovsmose no tocante ao processo de ensino e aprendizagem da Matemática na perspectiva Crítica possuem um objetivo comum que é o papel do estudante na sociedade, atribuindo especial atenção à sua formação crítica. Com este entendimento, os pesquisadores supracitados preocupam-se em oferecer oportunidades para que o estudante possa participar ativamente do seu processo de aprendizagem, tomando para si a responsabilidade, tornando-se ator principal do processo. Neste sentido buscam incentivar o uso de práticas pedagógicas onde os alunos sejam estimulados a procurar soluções para problemas, formularem questões e hipóteses, testar estas hipóteses, justificarem seus resultados e apresentarem argumentos para defender suas ideias. Atitudes estas que se apresentam essenciais para o desenvolvimento crítico do estudante. Diferentemente de João Pedro da Ponte que se dedica ao estudo e incentivo de práticas pedagógicas que possuem este perfil, mais especificamente a Investigação Matemática, Alro e Skovsmose (2010) debruçam suas pesquisas nos diálogos que ocorrem por meio destas práticas, atribuindo especial importância à qualidade do diálogo, enfatizando o incentivo ao diálogo como primordial para o sucesso da investigação.

Na sequência, descreveremos uma atividade de Investigação Matemática desenvolvida por um grupo de alunos, algumas interações que ocorreram durante seu desenvolvimento e nossas considerações a respeito da configuração do diálogo nesta atividade.

\section{ASPECTOS METODOLÓGICOS}

\section{A pesquisa}

Os resultados aqui apresentados são parte da pesquisa de mestrado profissional (em andamento) da segunda autora. Nesta pesquisa, são analisadas diferentes atividades de Investigação Matemática com o intuito de observar a ocorrência ou não de diálogos nas interações. Para este artigo, estabelecemos como foco de análise uma atividade desenvolvida por um grupo de alunos do 1 응 Ano do Ensino Médio de um Colégio Público da Cidade de Apucarana. A atividade em questão foi $A$ Lenda dos Vampiros, com duração de 100 minutos, duas aulas de 50 minutos cada.

\section{O encaminhamento}

Foi proposto aos alunos o desenvolvimento de uma atividade investigativa, na qual deveriam entender o problema, sugerir alternativas de solução, analisar seus resultados e, se preciso, reestruturar suas hipóteses. Nesse desenvolvimento, o professor deveria ser um guia ao aluno, um apoio, não apresentando respostas prontas e, sim, questionando-o e conduzindo-o na busca de hipóteses, argumentos e justificativas para seu encaminhamento.

Os alunos trabalharam em duplas e ficou acordado que deixassem registradas no caderno suas ideias e possíveis estratégias utilizadas para a resolução da atividade. 
Descreveremos aqui algumas interações ocorridas. Neste momento, os alunos serão identificados como A, B, C, etc.

\section{A coleta de dados}

No que se refere à coleta de dados para esta pesquisa, recorremos a técnicas próprias da análise qualitativa, quais sejam: a produção escrita do aluno, a gravação em vídeo, a observação e as anotações da professora/pesquisadora.

\section{A condução da análise}

A análise dos dados foi realizada de acordo com nosso objetivo: identificar a presença de atos dialógicos nas interações, possibilitando, assim, a caracterização (ou não) das interações como um diálogo na perspectiva de Alrø e Skovsmose (2010). Para realizar essas análises, transcrevemos as gravações e as comparamos com as anotações da pesquisadora e ainda com as anotações dos alunos, com o intuito de acrescentar algo que não tivesse sido observado nas gravações.

\section{INVESTIGAÇÃO MATEMÁTICA EM SALA DE AULA: Descrição e análise das interações estabelecidas}

Nesta seção, apresentaremos a atividade desenvolvida, as interações ocorridas durante esse desenvolvimento e, na sequência, a análise dessas interações. O objetivo desta atividade foi relembrar alguns conceitos matemáticos relacionados à potenciação e à função exponencial.

\section{A Lenda dos Vampiros}

Iniciamos a aula com uma conversa informal sobre a existência ou não de vampiros. Para tal, questionamos:

1. Prof. . : Vocês acham que existem vampiros? Acreditam na existência deles?

2. A: Eu acredito!

3. Alguns alunos disseram que não acreditavam.

4. Prof. a: Vamos supor que existam. Do quê os vampiros se alimentam?

5. A: Se alimentam de sangue?

6. Prof.a.: Muito bem... Qualquer tipo de sangue?

7. A: Sangue de vaca!

8. B: Sangue humano!

9. Prof.. : Sangue humano ou de vaca? Mais alguém quer falar?

10. D: De gente, professora, sangue de gente! Eu vi na TV.

11. Outros alunos concordaram com ela.

Iniciou-se uma série de exemplos: de onde teriam visto, onde teriam ouvido, etc., cada um argumentando o que tinha ouvido a respeito.

12. Prof.. : E então, $A$ ? Você acha que é sangue humano ou de animal?

13. A: Lembrei, "prof". É de gente!

14. D: Quando os vampiros "morde" uma pessoa, ela também vira vampiro.

15. Prof.. : Também ouvi falar isso. Vamos supor, então, que isso seja real;que quando os vampiros mordem um ser humano, este se torna vampiro. Também ouvi dizer que eles se alimentam só uma vez por semana... 
16. A: É isso...Uma vez por semana!

$O$ restante dos alunos concordou com ela.

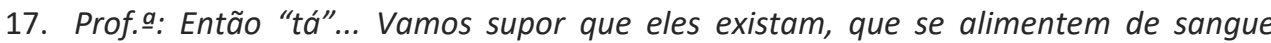
humano, que cada vez que mordem um humano, este se torne vampiro, e que o vampiro se alimente apenas uma vez por semana. OK?

Ao falar sobre os vampiros com os alunos, procuramos envolvê-los no assunto, nos empenhando para que todos estivessem em sintonia (alunos e pesquisadora), o que, segundo Alrø e Skovsmose (2010), significa que estão a "estabelecer contato". Observamos, ainda, que a pesquisadora (professora) se esforçou para ouvir a opinião dos alunos, interagindo, voltando ao que considera equívoco do aluno (linha 12: "E então A? Você acha que é sangue humano ou de animal?"), auxiliando-os a chegar a um consenso para prosseguir na investigação. Observamos que, naquele momento, esse consenso era necessário para dar andamento à atividade.

Após a fala da professora (linha17), o aluno F posicionou-se:

18. F: Vampiros não existem!

19. Prof. : Não?! Porque acha isso?

20. F: Eu não quero ser um vampiro.

21. Risos da turma

22. Prof. : Como assim? Porque acha que seria vampiro?

23. F: Se existissem, todos nós seríamos vampiros.

24. D: É... Verdade!

Alguns alunos concordaram, outros não entenderam a conclusão dos colegas.

25. Prof.. : Mas porque você acha isso?

26. F: Imaginei!

27. D: Não sei explicar, mas pensamos nisso!

28. Prof. ․: Hum... Vamos ver se vocês têm razão. Mais alguém concorda com isso?

Naquele momento, ocorreram discussões sem nenhuma conclusão. Ocorreram, ainda, várias argumentações, um tentando convencer o outro, porém, nenhuma delas com fundamento convincente.

29. Prof.. : Vamos fazer o seguinte: já que $F$ e $D$ acham que, se existisse um vampiro, então todos nós seríamos vampiros, vamos tentar descobrir se isso é verdade. Se for verdade o que eles falaram, e como nós não somos vampiros, então não existem, certo?

30. Alunos: Certo, certo...

31. A: Mas, como vamos fazer?

32. C: É... Não sei...

33. Prof. : $\mathrm{O}$ que nós sabemos sobre os vampiros até agora?

34. B: Que pega o sangue do outro.

35. D: Que, quando pega, o outro também vira vampiro.

36. Prof. : Que mais?

Os alunos ficaram pensando, e repetiram o que já tinha sido falado antes.

37. Prof. - : Quantas vezes por semana isso acontece?

38. Uma, uma (vários alunos ao mesmo tempo).

39. Prof. - Então, é isso. Vamos pensar: se hoje temos um vampiro, e ele morde alguém, quantos vampiros teremos semana que vem?

40. Todos: Dois.

41. Prof. : E quantos teremos na outra semana?

Discussão generalizada; uns diziam três, outros quatro, etc. 
42. Prof. : Façam o seguinte: montem uma tabela e discutam com os colegas para saber a quantidade de vampiros que teremos na outra semana, e na outra, e na outra...

Observou-se que, nessa interação, a professora continuou fazendo com que os alunos expressassem suas ideias e trabalhou no sentido de dar ouvidos a todas elas, associando-as, para construir uma estratégia de verificação da questão: a existência dos vampiros. Notamos que os alunos se posicionaram, e a professora avaliou e reformulou o que fora dito. Essas ações são exemplos de atos dialógicos presentes nessa interação.

Após alguns minutos, solicitamos aos alunos que passassem os valores que tinham sugerido para quantidades de vítimas dos vampiros por semana. Os alunos foram nos falando como haviam feito, e fomos transcrevendo para a lousa, como mostrado na Tabela 1.

Tabela 1 - Total de vampiros em relação ao número de semanas

\begin{tabular}{c|c}
$\mathbf{T}$ (semanas) & Total de vampiros \\
\hline $\mathbf{0}$ & 1 \\
\hline $\mathbf{1}$ & 2 \\
\hline $\mathbf{2}$ & 4 \\
\hline $\mathbf{3}$ & 8 \\
\hline $\mathbf{4}$ & 16 \\
\hline$\ldots$ & $\ldots$ \\
\multicolumn{2}{c}{ (Fonte: autores) }
\end{tabular}

43. Prof. : OK, muito bem! Agora, olhem aqui. O que está acontecendo com o total de vampiros de uma semana para a outra?

44. B: Dobrando.

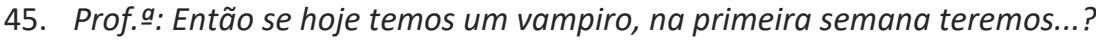

46. Alunos: Dois.

47. Prof. : Na segunda?

48. Alunos: Quatro.

49. Prof.. : Na terceira?

50. Prof. : Oito.

51. Prof. : Muito bem! Vocês são ótimos! Agora, quero saber: quantos vampiros teríamos na sexta semana?

O silêncio tomou conta da sala nesse momento.

52. Prof. : Pensem um pouco, conversem com o colega e tentem chegar à quantidade de vampiros na sexta semana.

Depois de alguns instantes:

53. H: Professora, vai ser sessenta e quatro.

54. Prof. a. É? Como você chegou a esse resultado?

55. H: É que está dobrando.

56. Prof. : Muito bem!

Apesar de parecer um jogo de perguntas e repostas, é possível observar que a atitude da pesquisadora é levar os alunos a pensarem. Naquele momento, ela tentou perceber as perspectivas dos alunos ao perguntar como $\mathrm{H}$ havia chegado à resposta de sessenta e quatro. Diante da observação feita por $\mathrm{H}$, começamos a explorar a tabela que havíamos acabado de construir. 
57. Prof. a : Agora eu queria saber quantos morcegos teríamos depois de 20 semanas. Alguém sabe quantos?

58. A: É muito!

59. B: Não vai dar para fazer... "Péra" aí!

60. Prof.. : Vou dar uma dica: tentem associar o número de semanas com o número de vampiros.

61. Alunos: Hã? Como? Como assim?

62. Prof.. : Assim: Na semana zero deu 1...hum... Esse é mais difícil. Vejam aqui: na semana 1 deu dois, na semana dois deu 4... Como podemos escrever o número de vampiros em função do número de semanas?

63. D: Multiplicando um pelo outro.

64. Prof. : Como?

65. D: Não...

66. A: Multiplicando a semana por 2.

67. D: Como?

68. A: Assim, "ó": 2 vezes a semana que quer... "ó"... primeira semana, duas vezes 1 dá dois, segunda...

69. Prof. : Então, tentem para mais alguns números e vejam se está correto.

Depois de alguns instantes:

70. D: Não dá... não dá para o oito...

71. Prof. $\underline{\text { : }}$ Todo mundo já fez? Dá certo assim?

72. Alunos: Não

73. Prof. ‥ Então não é essa regra gente... Não é essa associação que devemos fazer entre as semanas e o número de vampiros. Vamos pensar outra estratégia...

74. B: Ah... eu não sei!

75. C: $E_{\text {... }}$

76. Prof. : Pessoal, pensem em outra função que estudamos esses dias..

77. A: Linear!!!

78. Prof. $\underline{\text { : }}$ Será?

79. A: Não sei...

80. Prof.. : Não é para falar qualquer uma... sem analisar... Tem que ver as propriedades...Vamos fazer o seguinte: fatorem o número de vampiros...

Alguns minutos depois:

81. F: O número quatro poderia ser substituído por 2 . 2.

82. B: O oito é... Então é 2. 2. 2.

83. Prof. : Isso, Muito bem! Continuem!

Naquele momento, observamos o aluno B explicando para os colegas como havia feito. Nessa interação, mais uma vez, vimos a professora deixando os alunos exporem suas ideias e testando-as para ver se estavam corretas. Também percebemos os alunos posicionarem-se, avaliarem-se, mudarem de estratégias e perceberem os equívocos. Notamos que a professora continuou dando feedback, ou seja, avaliando e ainda desafiando os alunos a mudarem de estratégias e explicarem como haviam chegado às suas conclusões. Quando o aluno $F$ (linha 81) disse como poderia representar o número quatro, logo o aluno $B$ (linha 82) conseguiu entender o colega e dar sua resposta da questão. Torisu (2014) ressalta que esses atos dialógicos permitem aos alunos uma liberdade maior para expor suas ideias, sendo esse um processo importante para a aprendizagem.

Foi possível observar, nas ações da professora, seu empenho para que os alunos reconhecessem um procedimento específico para representar os valores. Por isso, a todo o momento demonstrou curiosidade e procurou desafiar os alunos a proporem outras maneiras de representar os mesmos valores, como, por exemplo, a multiplicação entre os elementos envolvidos e a fatoração. 
Solicitamos então que os alunos encontrassem outra maneira de escrever o número 8 , além da forma 2. 2. 2. Os alunos demonstraram dificuldades em entender e, com o intuito de que não desanimassem, retomamos os conceitos de potenciação. Na sequência, com a participação dos alunos, completamos a tabela apresentada na Tabela 1, ficando como representado na Tabela 2.

Tabela 2- Total de vampiros em relação ao número de semanas

\begin{tabular}{c|c}
$\mathbf{T}$ (semanas) & Total de vampiros \\
\hline $\mathbf{0}$ & $2^{0}$ \\
\hline $\mathbf{1}$ & $2^{1}$ \\
\hline $\mathbf{2}$ & $2^{2}$ \\
\hline $\mathbf{3}$ & $2^{3}$ \\
\hline $\mathbf{4}$ & $2^{4}$ \\
\hline$\ldots$ & \multicolumn{2}{|c}{${ }^{2}$} \\
\hline \multicolumn{2}{c}{ (Fonte: autores) }
\end{tabular}

Na sequência, questionamos sobre a relação entre os expoentes da coluna dois com o número de semanas da coluna um. Mas, antes disso, alguns alunos já haviam se posicionado, dizendo que o expoente era igual ao número de semanas. Aproveitando a dica, questionamos:

84. Prof.. : Como poderíamos calcular o total de vampiros em um período longo de tempo?

85. D: Seria $y=x .2$

86. Prof.a: Será? Vamos verificar se realmente é verdade.

A validação das repostas por parte dos alunos é um processo importante, pois é o momento da investigação em que o aluno tende a refletir, a reformular, pensar alto, reconhecer e perceber que seu raciocínio está correto ou não (PONTE; BROCARDO; OLIVEIRA, 2013); (ALR Ø; SKOVSMOSE, 2010). Para as primeiras semanas, as respostas satisfaziam o problema. Porém, quando chegaram à terceira semana, perceberam que não era possível encontrar os valores utilizando a estratégia sugerida por $D$ (linha 85 ). Observa-se que a professora não disse que a solução encontrada por D estava errada. Ela, ao contrário disso, incentivou os alunos a testarem essa hipótese. Após concluírem que a solução oferecida por $D$ não era a correta, a professora continuou a questionar:

87. Prof.. : Então... Não é isso, né? Observem a tabela de novo... Como poderíamos fazer para calcular o total de vampiros daqui a 10 semanas?

Após várias tentativas, os alunos chegaram à conclusão de que o expoente deveria ser igual ao número de semanas.

88. G: Fazer $2^{10}$.

89. Prof.a. Isso...Calculem e vejam qual o resultado.

90. F: 1024

91. Prof.. : O que significa esse valor?

93. Prof.. : Agora calculem quantos vampiros teremos daqui a 33 semanas. 
94. I: Os vampiros não existem!

95. Prof. $\underline{\text { : }}$ Porque não?

96. I: Porque já "tá" maior que a população mundial.

97. Prof.a.: Qual é o total da população mundial?

98. J: 120 bilhões de habitantes.

99. I: Eu falei que não existe!

Foi muito interessante observar a conclusão do aluno I. Anteriormente, ele tinha afirmado que não existiam vampiros, porque, caso existissem, toda a população seria de vampiros. Consequentemente, ele também seria um vampiro, o que ele não queria. Quando observou que, de acordo com nossas hipóteses, em 33 semanas a quantidade de vampiros seria maior do que a população atual, rapidamente enfatizou que não existiam vampiros. Ele estava certo!

Como não havia tempo para pesquisarem a população atual, informamos que a população mundial estava em torno de seis bilhões de habitantes. Quando I (linha 94) afirmou que os vampiros não existem, ele emitiu uma opinião que logo foi percebida pelo restante dos colegas. Isso implica em uma forma de posicionamento, pois, ao emitir sua opinião, ele também a defende, enfatizando seu pensamento (linha 96).

Nosso objetivo em relação aos conceitos matemáticos nesta atividade foi reforçar/relembrar conceitos de funções exponenciais. Porém, em nenhum momento isso foi explicitado aos alunos. A atividade iniciou-se como uma curiosidade, mas, no decorrer da mesma, os alunos foram envolvidos e, sem perceberem, trabalharam os conceitos matemáticos, fonte de nosso interesse.

$\mathrm{Na}$ aula seguinte, voltamos ao problema e discutimos com os alunos sobre a função exponencial e suas propriedades. Utilizando um software, os alunos foram incentivados a investigar o gráfico da função e, assim, compreenderem o crescimento na quantidade de vampiros.

A interação começou tímida, mas, no decorrer da mesma, os alunos foram interagindo um pouco mais. Pudemos, então, observar que vários atos dialógicos, que podem caracterizar uma interação como um diálogo, estavam presentes no desenvolvimento desta atividade.

\section{PARA INICIAR AS CONTRIBUIÇÕES}

Nosso intuito com a publicação deste artigo é argumentar a favor do uso da Investigação Matemática como prática pedagógica em sala de aula. Para tanto, procuramos diagnosticar se a Investigação Matemática propiciava o diálogo, conforme a caracterização de Alrø e Skovmsose (2010). Ao analisar as interações entre alunos/alunos e alunos/professores, foi possível inferir que vários atos dialógicos, necessários para que uma conversação se configure um diálogo, estavam presentes. Desse modo, o diálogo foi oportunizado pela atividade de Investigação Matemática.

Portanto, para esse grupo de alunos e para essa atividade, entendemos que a Investigação Matemática proporcionou o diálogo, o qual, de acordo com nosso referencial teórico, tem grande potencial para promover a aprendizagem.

Do mesmo modo que Ferruzzi e Almeida (2015, p. 392) observaram que diversas ações dos envolvidos 
[...] não são exclusivas de atividades interativas, porém, a diferença reside no fato de que, em interação, estas ações são, muitas vezes, explicitadas para o outro, atuando como auxiliadoras e, ao mesmo tempo, atuando como reorganizadoras do pensamento, promovendo a estruturação e novas aprendizagens. Este fato se deve à necessidade de o indivíduo se fazer entender, e, neste ato, o indivíduo realiza uma reflexão do seu pensamento. Enquanto os alunos realizam seus procedimentos em grupo, eles falam a respeito do que fazem, perguntando, e, muitas vezes, explicando o que estão fazendo. Suas falas, além de acompanharem a realização da atividade, a orientam, uma vez que, ao deparar-se com sua fala ou sua escrita, o aluno pode observar um procedimento equivocado e corrigi-lo por si só, como se fosse uma interação consigo mesmo.

Temos ciência de que a Investigação Matemática não é a única prática que oportuniza a interação e a ocorrência dos atos dialógicos. Porém, com vistas a incentivar seu uso em sala de aula é que nos debruçamos em investigar essa prática nesta pesquisa. Isso não significa que outras práticas não devam ser incentivadas e que seus resultados sejam discutidos como o que aqui apresentamos.

Não podemos deixar de enfatizar que outras atividades com grupos diferentes de alunos estão sendo realizadas (e podem ser realizadas por outros pesquisadores), para que tenhamos mais subsídios para argumentar a favor da inserção de atividades de Investigação Matemática em sala de aula como uma prática desencadeadora de aprendizagem.

Desse modo, fica aqui nossa contribuição para futuros debates a respeito do tema e o convite para pesquisas que nos apontem mais resultados com base nesse referencial. 


\title{
Mathematical research and its contribution to learning
}

\begin{abstract}
This article intends to start a discussion about Mathematical Research in the classroom, arguing in favor of its insertion, understanding it as a helper in the learning process. For this, we try to identify in the development and analysis of some activities the presence of some acts, called dialogic ones, that if present in the interactions can subsidize to this understanding. According to Alr $\varnothing$ and Skovsmose (2010), this presence can be characterized as dialogue and "interactions characterized as"dialogues"are interactions that possess qualities that positively influence learning" (Ferruzzi and Almeida, 2015). , Pp. 378). The analysis of the interactions, based on our theoretical framework, allowed us to find evidence that Mathematical Research as a pedagogical practice provides the dialogue and thus we infer about its ability to positively influence learning.
\end{abstract}

KEYWORDS: Dialogue. Mathematical research. Learning. 


\section{REFERÊNCIAS}

ALRO, H.; SKOVSMOSE, O. Diálogo e Aprendizagem em Educação Matemática. Tradução de Orlando Figueiredo. Belo Horizonte: Autêntica, 2010.

CUNHA, D.S.I.Investigações Geométricas: desde a formação do professor até a sala de aula de Matemática. Mestrado em Ensino de Matemática - UFRJ, Rio de Janeiro, 2009.

CYRINO, M.C.C.T. A prática pedagógica do professor de Matemática em sala de aula. In: Encontro Paranaense de Educação Matemática, 2002, Foz do Iguaçu. Anais do VII Encontro Paranaense de Educação Matemática. Foz do Iguaçu: UNIOESTE, 2002. p. CD-ROM.

FERRUZZI, E. C.;ALMEIDA, L. M. W. de. Diálogos em modelagem matemática. Cienc. Educ. (Bauru, v. 21, n. 2p. 377-394 June 2015. Acessado em http://dx.doi.org/10.1590/1516-731320150020008.

OCDE. Organização de cooperação e de desenvolvimento econômico. Programme for InternationalStudent Assessment (PISA). Resultsfrom PISA 2015. 2016. Disponível em: http://www.oecd.org/pisa/PISA-2015-Brazil-PRT.pdf. Acesso em: 02 mar. 2017.

OLIVEIRA, H. M.; SEGURADO, M. I.; PONTE, J. P da.Explorar, investigar e discutir na aula de matemática. In P. Abrantes, J. P. Pontes, H. Fonseca, L. Brunheira (Eds), Investigações matemáticas na aula e no currículo. Lisboa: Projeto MPT e APM, 1999, p. 207-213. Lisboa: APM, 1999.

ONUCHIC, L. de la R. Ensino-Aprendizagem de matemática através da Resolução de Problemas. In: BICUDO, M. A. V. (org.). Pesquisa em Educação Matemática: concepções e perspectivas. São Paulo: Editora UNESP, 1999.

PONTE, J. P. da, et al. Investigando as aulas de investigações matemáticas. In P. Abrantes, J. P. Pontes, H. Fonseca, L. Brunheira (Eds), Investigações matemáticas na aula e no currículo. Lisboa: Projeto MPT e APM, 1999, p. 133-151.1999.

PORFÍRIO, J.; OLIVEIRA, H. Uma reflexão em torno das tarefas de investigação. In P. Abrantes, J. P. Pontes, H. Fonseca, L. Brunheira (Eds), Investigações matemáticas na aula e no currículo. Lisboa: Projeto MPT e APM, 1999, p. 111118, 1999. 
em:http://www2.ifrn.edu.br/ojs/index.php/HOLOS/article/view/3607. Acesso em: 30 maio 2017. doi:http://dx.doi.org/10.15628/holos.2015.3607

SKOVSMOSE, O. LandscapesofInvestigation. ZDM, v. 33, n. 4, p.123-132, ago. 2001.

TORISU, E. M. Diálogo em sala de aula de Matemática: uma forma de comunicação na cooperação investigativa. SIMPEMAD-Simpósio Educação Matemática em Debate, v. 1, p. 266-278, 2014.

\footnotetext{
Recebido: 2017-06-22

Aprovado: 2018-03-21

DOI: $10.3895 /$ rbect.v11n3.6058

Como citar: FERRUZZI, E. C.; COSTA, J. A. A. Investigação matemática e seu aporte para a aprendizagem. Revista Brasileira de Ensino de Ciência e Tecnologia, v. 11, n. 3, 2018. Disponível em: <https://periodicos.utfpr.edu.br/rbect/article/view/6058>. Acesso em: $\mathrm{xxx}$.

Correspondência: Juliana Aparecida Alves da costa - julian.mat@hotmail.com Direito autoral: Este artigo está licenciado sob os termos da Licença Creative Commons-Atribuição 4.0 Internacional.
}

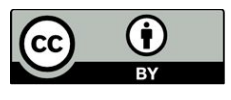

